\title{
Potential implications of solar radiation modification for achievement of the Sustainable Development Goals
}

\author{
Matthias Honegger ${ }^{1,2,3}$ (D) Axel Michaelowa ${ }^{1,4}$ (D) Jiahua Pan $^{5,6}$
}

Received: 19 June 2020 / Accepted: 11 May 2021 / Published online: 17 June 2021

(c) The Author(s) 2021

\begin{abstract}
Solar radiation modification, particularly stratospheric aerosol injection, holds the potential to reduce the impacts of climate change on sustainable development, yet could itself generate negative impacts and is subject to intense scholarly debate based on relatively little evidence. Based on expert elicitation involving over 30 individuals with backgrounds across the domains of the United Nations' Sustainable Development Goals (SDGs), we identify a broad range of potential implications of solar radiation modification for the SDGs. Depending on design and application scenarios, applications could potentially assist in the pursuit of several of the goals by limiting temperature rise and limiting acceleration in atmospheric water cycles as well as extreme weather events. However, by adding to particulates, introducing an additional layer of complexity and potential for conflict in global governance, as well as otherwise altering planetary environments, they might also detract from the pursuit of SDGs and introduce novel risks. The overall impact of solar radiation modification on sustainable development is currently highly uncertain and dependent on climate change mitigation pathways and governance. We identify key areas for further transdisciplinary research the pursuit of which might reduce some uncertainty and help inform emerging governance processes.
\end{abstract}

Keywords Solar radiation modification · Sustainable Development Goals · United Nations $\cdot$ Co-benefits $\cdot$ Side effects $\cdot$ Risk

Matthias Honegger

honegger@perspectives.cc

1 Perspectives Climate Research, Freiburg i.B., Germany

2 Copernicus Institute for Sustainable Development, Utrecht University, Utrecht, The Netherlands

3 Institute for Advanced Sustainability Studies, Potsdam, Germany

4 University of Zurich, Zurich, Switzerland

5 Institute of Ecocivilization Studies, Beijing University of Technology, Beijing, China

6 Research Centre for Sustainable Development, Chinese Academy of Social Sciences, Beijing, China 


\section{Introduction}

The Paris Agreement aim of limiting global warming to $1.5-2{ }^{\circ} \mathrm{C}$ above pre-industrial levels is crucial for the pursuit of the Sustainable Development Goals (SDGs) but highly ambitious: A balance of emissions and removals of greenhouse gases (GHGs) needs to be achieved by approximately 2050 (for retaining a 66\% likelihood of limiting warming to $1.5^{\circ} \mathrm{C}$; IPCC, 2018) or by approximately 2075 (with the same likelihood to reach the $2{ }^{\circ} \mathrm{C}$ target). Achieving this balance would require an unprecedented transformation (Michaelowa et al., 2018). An immediate fivefold increase in ambition of current national mitigation pledges would be needed in order to reach the $1.5^{\circ} \mathrm{C}$ target; a threefold increase would be needed for $2{ }^{\circ} \mathrm{C}$. With the new US administrations return to the Paris Agreement and the enhanced Chinese ambition (carbon neutrality before 2060), there is hope for an acceleration in climate action (Pan, 2020a). Nonetheless, most national mitigation targets have remained at the level declared in 2015 and rapidly industrializing economies such as India and the ASEAN countries have seen renewed and continued increases in emissions from fossil fuel combustion (IEA, 2020; Pan, 2020b). Attention has in recent years increasingly shifted to the "removals" part of the equation and numerous ideas for large-scale capture and storage of $\mathrm{CO}_{2}$ are being discussed. There is, however, growing recognition that such technologies or practices face the same political and economic challenges that impede emissions reductions measures (Bellamy, 2018; Honegger and Reiner, 2017). It is thus plausible that global average temperatures are headed to an increase of over $3{ }^{\circ} \mathrm{C}$ by the end of the century and more beyond.

Solar radiation modification (SRM), in particular stratospheric aerosol injection (SAI), is increasingly capturing attention for its potential to limit climate change impacts even if atmospheric GHG concentrations continue to increase. The potential implications of applications of SRM on various dimensions of sustainable development are, however, not well understood.

SRM differs from GHG mitigation (emissions reductions and $\mathrm{CO}_{2}$-removal) in three key ways: (i) direct deployment costs are potentially low; (ii) effects are potentially rapid and large, and (iii) it does not treat the root cause of climate change: the concentration of greenhouse gases in the atmosphere.

Use of SRM would create its own risks and would only make any sense in a world experiencing or expecting severe climate change impacts. As such, consideration of SRM takes place in a risk-risk context (whereby the risks of application are judged against the risks from climate change without SRM). Considering the impacts of SRM in isolation can be misleading, as SRM's sole raison d'être is reduction or avoidance of climate impacts stemming from elevated greenhouses gas concentrations.

Equally, it would be wrong to judge SRM solely by its potential to influence global average temperature. In fact, if this was the sole metric that mattered, SRM would already have been deployed to prevent harm occurring, for it is the only known measure that could halt or reverse warming with close to no delay. To be relevant, assessment of SRM therefore needs to enhance our understanding of potential effects across a multitude of socially relevant parameters, rather than a single one.

While several reports and studies have sought to synthesize the scientific understanding of how SRM approaches and concrete interventions could be expected to perform (Lawrence et al., 2018; Royal Society, 2009; Schäfer et al., 2015; National Academies of Science, 2015), only limited research has explored the potential, highly interconnected implications of SRM on the pursuit of a multiplicity of social 
objectives. Honegger et al. (2018) being a notable exception, so far no peer-reviewed publication has comprehensively examined the potential SRM implications for the SDGs. Much like climate change impacts being a function of adaptive capacity, the relative importance of implications of SRM use would significantly depend on specific societal circumstances across the globe. Actual predictions of such dynamics are nearimpossible for such highly interconnected issues across geographies and socio-economic and political systems over time. Yet, systematic exploration of potential implications can nonetheless provide an important foundation for making well-informed decisions including on whether to rule out particular SRM approaches altogether. It is important to avoid a future situation where there is political pressure for a quick decision on SRM when the potential implications are still unclear.

\subsection{A review enriched by expert elicitation}

Our contribution seeks to synthesize present understanding of complex possible outcomes from SRM. We understand a synthesis to not merely represent a neutral summary, but an additional step of sense-making, which is shaped through a particular set of personal lenses. Endeavoring to draw on a globally relevant diverse basis (both in geography and SDG domains), we invited a group of individuals to critically examine and contribute to our review. Our approach to synthesizing the present understanding of potential implications - including among others bio-physical, environmental, social, economic, political, and institutional - thus offers a distinct, interpretative quality of understanding, beyond what a literature review could deliver on its own. It leverages participants' multiple geographic and disciplinary backgrounds for developing an enhanced, albeit preliminary, map of potential implications (and open questions) across the 17 SDGs.

The expert elicitation involved over 30 individuals with expertise across all the 17 goals and broad geographic coverage of over 20 countries. Individuals were selected for their complementary expertise to collectively span the 17 SDGs, as well as potentially concerned areas and institutions of international environmental governance. Academic fields included in the process spanned biology, earth systems modelling, economics, engineering, (environmental/humanitarian) law, environmental studies, innovation studies, geophysics, international politics, international relations, philosophy, physics, sociology, science and technology studies, sustainable development, and policy analysis. Policy and institutional experience furthermore included various multilateral, international, and domestic governance contexts pertaining to the environment, climate change, food and agriculture, energy, and water. The group also spanned eastern and western Europe, western Africa, central and southeast Asia, as well as North and South America (see Tab s1: Experts involved in the review process). The role of the participants was to introduce their own background into our interpretation of the literature and its gaps rather than adding SRM expertise per se. They identified possible reasons for concern and potential research gaps rather than introducing answers. Participants critically responded to the review at an early stage, allowing for refining it, considering additional literatures, and identifying knowledge-gaps as well as open questions. Rather than an end-point, we see our synthesis as an opportunity to point to many unresolved issues surrounding SRM to inform emerging international governance processes. 


\subsection{Implications of SRM arising out of various physical and non-physical impact pathways}

The implications of SRM use identified by us arise from physical and non-physical impact pathways as well as their interactions. The following questions guide our review:

(A) To what degree might achievement of each SDG be influenced by SRM's effects on the climate system?

(B) What physical side effects could arise from particular forms of SRM deployment?

(C) To what degree might particular SRM deployment policies affect socio-economic, political, or even cultural dimensions and vice versa?

Against the counterfactual of no SRM intervention (orange arrow in Fig. 1), potential implications of SRM implementation strongly depend on three key conditions and their interaction: (a) atmospheric $\mathrm{CO}_{2 \mathrm{e}}$ concentration pathways, (b) SRM intervention design (choice of materials, intensity, scales, and location of interventions) and scenario (temporal choices in the intervention), and (c) adaptive capacity and resilience and general local governance capacities (Fig. 1). All three conditions are variously co-determined by environmental (physical) and human factors and respective impact pathways (including social, economic, and political).

To build the foundation for addressing the three questions in subsequent dedicated sections, the following section first discusses how $\mathrm{CO}_{2 \mathrm{e}}$ pathways and SRM design and application scenarios together determine SRM's physical effect on climate change impacts.

Fig. 1 Diagram of interactions between atmospheric $\mathrm{CO}_{2 \mathrm{e}}$ concentration pathways, climate impacts (with or without SRM), SRM design and scenario, SRM side effects (including social, economic, and political), and the modulating effect of local governance and adaptive capacities, and resilience. This review explores the present understanding of interlinked impact pathways on achievement of the SDGs

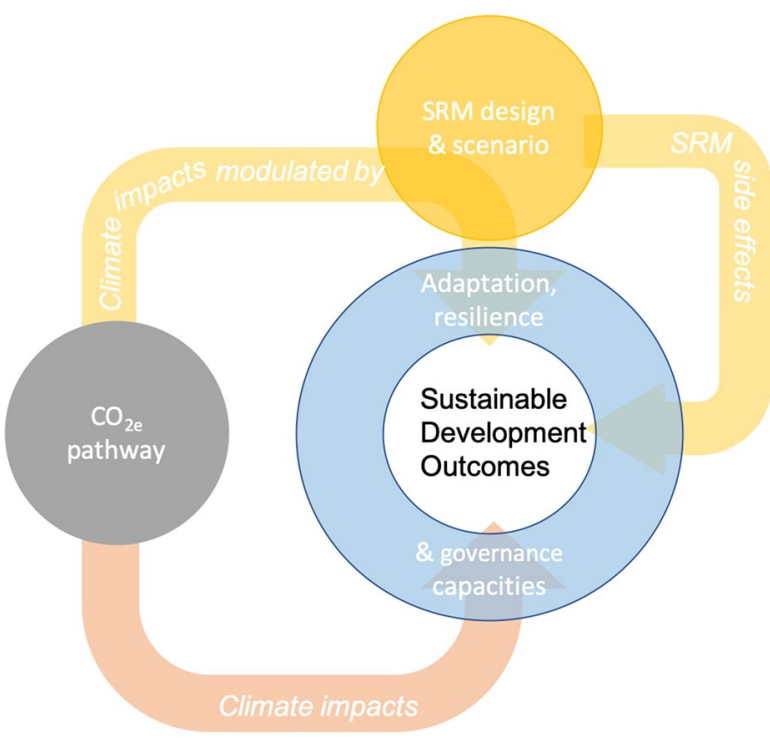




\section{How $\mathrm{CO}_{2 \mathrm{e}}$ pathways and SRM design and application scenarios shape SRM's physical effect on climate impacts}

The Intergovernmental Panel on Climate Change (IPCC) refers to SRM as the "intentional modification of the Earth's shortwave radiative budget with the aim of reducing warming" and it identifies three types of SRM differentiated by their loci of intervention: stratospheric aerosol injection (SAI), cloud modification, and surface albedo modification (see Table 1). SAI seeks to increase the amount of aerosol particles in the lower stratosphere at altitudes of around $20 \mathrm{~km}$, to scatter or reflect a small percentage of sunlight (Rasch et al., 2008). Cloud modification over land or water surfaces aims to modify levels of cloud reflectivity to influence global temperatures by "seeding" clouds with small particles that act as nuclei around which water vapor droplets form, either brightening clouds to reflect more sunlight away (in particular over heat absorbing dark ocean surfaces) or to thin higher altitude (cirrus) clouds to enhance transmission of radiative energy from the earth's surface back into space (the latter does not technically fit the IPCC definition of SRM, but we also include it here due to its functional relevance). Surface albedo modification could in principle be applied to any land or ocean surface by covering it with reflective materials or with plants that have a higher reflectivity resulting in local or regional cooling.

\subsection{Location of SRM intervention affecting weather and climate}

The distinction of where radiative forcing changes occur is important as it determines effects on regional and global climate variables and local weather patterns: interventions in the stratosphere (out of the "weather-sphere") seem to hold the greatest promise of delivering globally near-uniform albedo modification, namely, by SAI (Irvine et al., 2010; Ricke et al., 2010; Tilmes et al., 2013). Extreme forms of uneven deployment (e.g., solely in one hemisphere) could have serious unwanted effects on atmospheric circulation and the hydrological cycle, whereas near-uniform application may allow for improvements in comparison to non-application (Jones et al., 2011); cloud modification would face serious challenges to achieve an even distribution of radiative forcing changes at regional scales. While uneven distribution may in some cases be desirable in an attempt to meet multiple climate objectives (Kravitz et al., 2017, 2019), it may also introduce significant uncertainties and potentials for adverse changes in regional and transboundary weather patterns. Surface albedo modifications at local scale can be utilized for adaptation purposes, e.g., counteracting urban heat islands (Fink, 2013; Jandaghian and Akbari, 2018), to reduce energy costs for cooling buildings or for preserving glaciers. Many mitigation efforts may, furthermore, have albedo modification implications (notably large solar PV installations, ecosystem restoration, or tree planting). As it is hard to conceive covering sufficiently large areas with artificial materials or a particular breed of plants, local albedo modifications would be unlikely to achieve a globally significant and sustained cooling effect. Moreover, they could change local or regional weather patterns in unforeseen and undesirable ways (Muri et al., 2018).

Given very large uncertainties regarding the effectiveness of cloud and surface albedo modification techniques and given the particular interest in SAI due to its global nature, we not only focus in the following largely on SAI when discussing climate-related effects yet also address some side effects of other SRM approaches. 


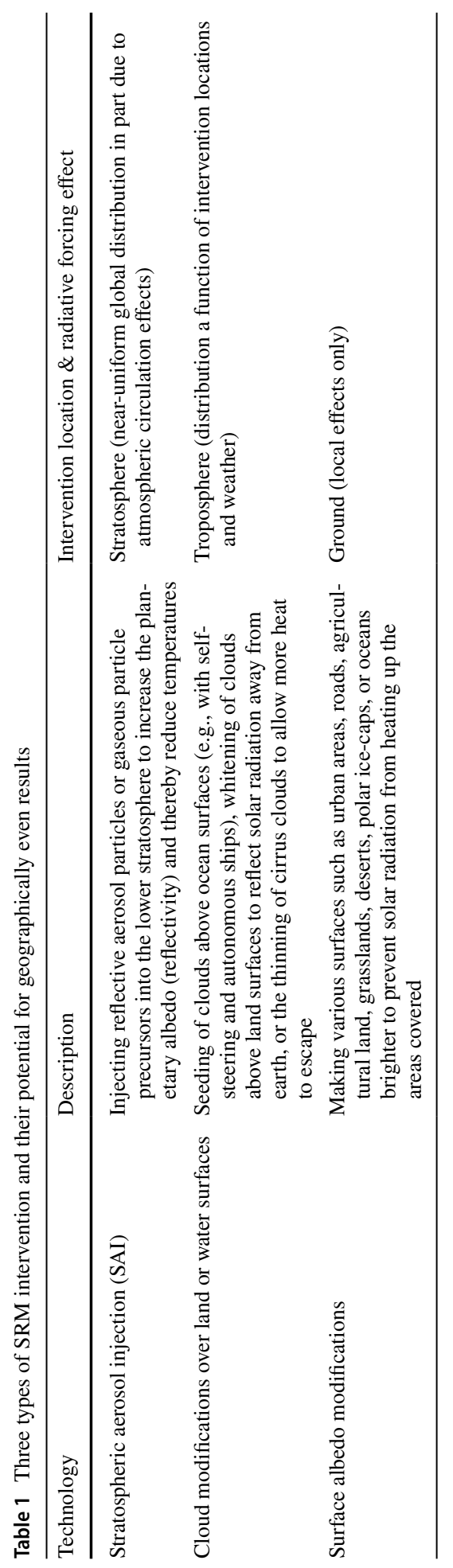




\subsection{Radiative forcing scenarios are key regarding overall outcomes}

Global SRM applications (perhaps through SAI) could be used to achieve various specific objectives, which are fundamentally differentiated by the timing and amount of warming that is to be counteracted. The most straightforward metric for globally near-uniform SRM application is radiative forcing induced over time. Figure 2 depicts two typical application scenarios: The first scenario type ("peak-shaving"; on the left) would apply SRM to avoid the peak of climate impacts corresponding to warming temporarily exceeding some particular level before global net-negative GHG emissions result in lowering atmospheric GHG concentration and corresponding threat level of climate change impacts (MacMartin et al., 2018). The second scenario type seeks to reduce the rate of warming, assuming that the best humanity could strive for in terms of addressing greenhouse gases would be to achieve net-zero global emissions (rather than net-negative global emissions) and thereby stabilize atmospheric concentrations at higher levels. Climate impacts scale roughly with radiative forcing and its rate of change (in the absence of SRM, this directly corresponds to atmospheric GHG concentrations). A variant of the above could take place in a situation where earth systems unexpectedly accelerate warming (e.g., due to release of methane from permafrost or clathrates) whereby SRM applications could seek to slow or halt such developments. For such emergency response scenarios, the uncertainties are particularly large.

While the relative strength of various causal mechanisms strongly depends on the assumed scenario (regarding $\mathrm{CO}_{2 \mathrm{e}}$ concentrations, SRM deployment design, and application), the mechanisms at work are generally the same, whether global SRM is used to shave off a peak warming, slow the rate of warming, or to halt unexpected acceleration in warming from environmental degradation. Their respective strengths would, however, differ and crucially depend on the magnitude of radiative forcing induced by GHG concentrations and that induced by SRM application: SAI is known to effect changes across a range of earth system variables (e.g., temperature, precipitation, and sea-level rise) at differing rates. It therefore appears to potentially achieve an imperfect limitation of climate change across climate variables at best. Deploying SAI in a scenario of unabated emissions and very high atmospheric GHG concentrations (>1000 ppm) to fully counteract the associated warming would likely result in substantial differences regarding precipitation in various regions (Curry et al., 2014; Ferraro et al., 2014; Ricke et al., 2010) thereby likely exacerbating some climate change impacts on the pursuit of SDGs. Yet, there is growing
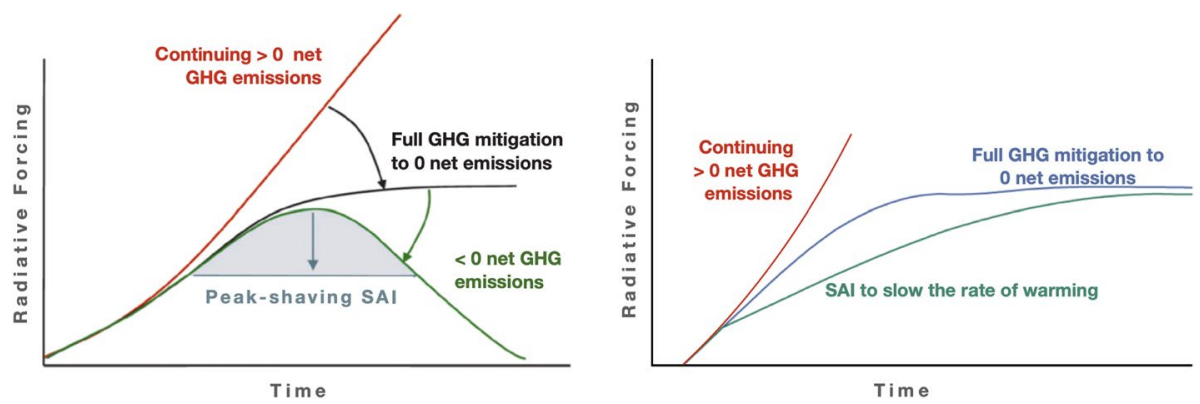

Fig. 2 Two different conceivable objectives for which global SRM could potentially be used with different implications for the pursuit of sustainable development: Shaving off the temperature peak (left, MacMartin et al., 2018) or limiting the rate of warming (right, Keith and MacMartin, 2015) 
evidence that SAI deployed to partially counteract elevated GHG concentration levels, e.g., reducing average warming from 3 to $1.5^{\circ} \mathrm{C}$ could potentially be beneficial across all key climate variables across all regions (Irvine et al., 2019; MacMartin et al., 2018; Jones et al., 2018; Pretis et al., 2018).

\section{Implications for the SDGs via climate change impact pathways}

Implications for the SDGs via climate change impact pathways can be differentiated into successful reduction of climate change-related damages via SRM, effects related to unplanned cessation of SRM ("termination risk"), and residual climate change impacts which SRM application cannot fully eliminate.

\subsection{Climate change damage reduction through successful SRM}

With the SDGs at high risk of becoming unattainable with accelerating climate change (Ansuategi et al., 2015), any SRM-induced slowing of climate change can have positive indirect effects for the achievements of a wide range of SDGs. Nerini and colleagues (2019) find implications of climate change across 16 SDGs on which there is presently published evidence: Evidence seems most readily available for material and physical wellbeing: work, prosperity, and economic productivity (World Bank, 2016a; Moore and Diaz, 2018), poverty eradication and employment, food, energy (van Vliet et al., 2016), clean water (Haddeland et al., 2014), and health (WHO, WMO, 2012; World Bank, 2016b). Nerini and colleagues (2019) also find evidence for climate change undermining efforts to strengthen education (Glewwe, 2005) and achieve justice and equality (Dankelman, 2002).

Modelling studies consistently suggest that limiting global warming to $1.5{ }^{\circ} \mathrm{C}$ rather than $3{ }^{\circ} \mathrm{C}$ through globally near-uniform deployment of SRM could result in relatively lower overall risk to achieving SDGs than warming of $3{ }^{\circ} \mathrm{C}$ without SRM would (MacMartin et al., 2018; Jones et al., 2018). The potential upside corresponds to avoidance of some of the currently anticipated harm across all SDGs arising from climate change (Table 2), yet with the caveat that any SRM would offer an imperfect limitation of climate change at best. Major uncertainties remain as to effects on the thermal layering of the atmosphere and by extension how atmospheric chemistry and weather might be affected by SAI (or other specific forms of SRM).

Climate change-related implications of cloud modification in particular are highly uncertain, given that cloud physics and chemistry are two of the most complex areas of climate science (Lohmann and Gasparini, 2017). Unless a deployment mechanism is found that allows relatively homogenous cooling, regional differences of impacts on the hydrological cycle (Rasch, 2010; Alterskjær et al., 2013) as well as on temperature (Cziczo et al., 2013; Storelvmo and Herger, 2014) could pose a serious challenge (Jones et al., 2011). Given the very limited work on potential delivery mechanisms, as well as very substantial uncertainties surrounding the physical and chemical properties of clouds, adverse implications on ecosystems and agricultural systems stemming from such regional differences cannot be ruled out. The potential socio-economic implications of unintentional regional effects from uneven applications in clouds or surface-based could pose challenges for equity, governance, and sub-national and international relations in affected regions. 
Table 2 Examples of potential implications of SRM via causal impact pathways of successful climate change damage reduction (Nerini et al., 2019; climate change damage reduction via SRM appears more likely in case of SRM achieving globally near-uniform distribution (likely involving SAI) and only partial counteraction of warming)

\section{SDG Potential implications of reducing climate change impacts with SRM}

$1 \quad$ Reduced pressure on the most vulnerable, poor populations

2 Less pressure on agricultural production due to weather extremes

3 Reduced health impacts from extreme heat, cold, and weather-related catastrophes

4 Better access to schools due to reduction in pressure from weather, water access, productivity, and health

5 Better access to education for girls due to less pressure to support families regarding basic needs

6 Better water access due to more steady precipitation, reduced evaporation, enhanced ecosystem stability

7 Higher reliability in energy generation due to less temperature extremes, less energy demand for cooling

8 More stable economic development due to reduced weather extremes

9 Less frequent disruptions to key infrastructure due to less weather extremes

10 Greater opportunities for disadvantaged populations to gain access to economic opportunities due to reduced pressure on access to basic needs

11 Reductions in urban heat island and weather extremes reducing pressures on urban settlements in particular in coastal areas

12 Lower climate impacts allowing to advance more rapidly toward high-value, low impact consumption and production patterns

13 Avoiding excessive levels of warming and risk of uncontrollable acceleration in temperature rise due to earth system feedbacks (Belaia et al., 2017)

14 Strong reduction in temperature (and potentially also some reduction in acidification) pressures on aquatic ecosystems (Kwiatkowski et al., 2015)

15 Strong reduction in pressures caused by continuous deviation from pre-industrial climate states on land ecosystems

16 Reduced potential for conflict due to climate change induced resource-conflicts and shortages

17 Reduced pressure for domestic spending on adaptation allowing for greater budgets for international cooperation

\subsection{Climate change risks of termination or excessive application}

SRM application runs the risk of abrupt termination should dramatic economic or political crises overturn application regimes. Sudden termination of global-level SRM deployment at substantial radiative forcing levels, not followed up by any replacement, could cause a rapid, significant change in key atmospheric climate variables (Trisos et al., 2018) with potentially massive harmful impacts (Irvine et al., 2012). At the same time, it would appear that global SAI application supported by several powerful countries would be resilient against all but the most extreme catastrophes given the relative ease and low costs of creating redundancy and replacing failing equipment (Parker and Irvine, 2018).

Excessive SRM application could also cause harm across SDGs: Given that even fully counteracting warming would result in partly excessive change to specific climate variables (notably precipitation), applications beyond full temperature compensation (even though potentially desirable to individual actors, e.g., governments that want to increase water availability through increased rainfall or aim to expand their land area in the long run due 
to sea-level decline) would have to be expected to cause severe harm across SDGs, especially if the rate of change of key climatic variables is high. Nevertheless, given that accurate dose-response effects of SRM deployments remain uncertain, it remains thus somewhat unclear what rates of application would have to be characterized as excessive or even how a social optimal rate could be determined scientifically or politically. The discussion here therefore remains at a conceptual and qualitative level of understanding.

\section{SDG implications arising from potential physical deployment side effects}

Potential physical side effects of the actual deployment infrastructure, sourcing, transporting, and deploying materials fundamentally depend on the type and specific form of deployment. While a few studies have addressed specific forms of deployment and identified associated physical side effects on human health and well-being as well as on aquatic or land-based ecosystems, to date, published empirical evidence does not seem sufficient to conclusively assess the feasibility and desirability of any specific delivery mechanism or substance. Since there is as of yet no clarity as to the actual technical design of SRM deployment (location of intervention(s), (air) transport vehicles, and materials), many different assessments would need to be undertaken to get a clear understanding of such side effects.

\subsection{Materials and distribution mechanisms}

The materials and the distribution mechanism utilized for altering albedo significantly affect the likelihood and severity of side effects.

For $S A I$, injection of sulfate aerosols or their precursor gases and alternatively calcite aerosols have been discussed. Sulfate aerosols have the advantage that there is a natural analogue for their application but they have the known downside of contributing albeit to a limited extent - to acidification (Visioni et al., 2018) of soils (SDGs 2, 15) and surface waters (SDG 14) as well as tropospheric sulfur pollution (SDG 3; Eastham et al, 2018). Sulfate aerosols could furthermore delay the recovery of the ozone layer, with important implications for health (SDG 3; Nowack et al., 2016; Pitari et al., 2014) and food production (Barnes et al., 2019). Calcite aerosols on the other hand could counter acidification (SDG 2,14,15) and might avoid most negative effects on tropospheric pollution and stratospheric ozone (SDG 3, 15; Dai et al., 2020; Keith et al., 2016). There is, however, potential for secondary effects on the ozone layer and cloud formation that could arise from aerosol interaction (Cziczo et al., 2019). Mining, grinding, and transportation of large quantities of materials could lead to air pollution with adverse implications for health and clean water (SDG 3, 6; Effiong and Neitzel, 2016) and result in additional and unwanted material flows into various ecosystems (SDG 14, 15).

For cloud brightening, direct side effects on health, ecosystems, and human infrastructures (SDG 3, 8, 14, 15) would depend on the particle materials, quantities, and locations of deployment and fuel-related and other emissions due to ship or aircraft operation. In case of ocean-based cloud seeding with seawater, this might be indistinguishable from natural sea-salt concentrations in the air above the ocean surface. But local deposition in coastal zones might contribute to corrosive effects on infrastructure (SDG 8) and the salinization of soils (SDGs 2, 15; Muri et al., 2015). In the case of cirrus cloud thinning, the necessary 
amounts of seeding substance are thought to be relatively small (Marshall, 2013). Impacts of jet fuel emissions resulting from deployment might be more significant in comparison (SDGs 3, 13).

Concepts for deliberate surface-based albedo modifications include large-scale modification of the reflectivity of land surfaces such as painting human settlements white, conserving reflective ice-masses, covering desert areas with reflective material, or selecting more reflective vegetation types as crops. Large-scale solar PV installation (on urban buildings, road surfaces, or in desert regions) could have both inadvertent and deliberate albedo modification effects while contributing to emissions reductions efforts. The types of materials used for such purposes matter, since no type of material can guarantee long-term persistence in the harsh environmental conditions to which it would likely be exposed. Furthermore, important earth system implications could arise from altering regional temperature distributions via surface-based albedo modification and by extension regional winds and associated movement of matter (e.g., desert dust that fertilizes ocean ecosystems).

Overall, reliable estimates of materials-related side effects are currently lacking given vast uncertainties over various delivery mechanisms' efficacy (Lohmann and Gasparini, 2017).

\subsection{Implications of changes in irradiation}

The expected relative increase in diffuse light can not only enhance productivity of photovoltaic power generation yet also reduce productivity of concentrated solar power (CSP) plants (SDG 7; Smith et al., 2017). Changes in the proportion of direct vs. scattered light affect plant growth unevenly, strengthening the growth of some species while reducing that of others, with respective implications for agricultural productivity (SDG 2), and life on land (SDG 15). Larger aerosol loads are expected to slightly whiten the sky and result in more colorful sunsets, with potential cultural implications (Table 3).

Some general observations can be drawn from the existing literature: Some physical side effects are likely to be proportional to the amounts of materials required (or inversely proportional to the reflexive efficiency of the materials). The type of materials used for SAI, cloud, or surface albedo modifications matters for a number of SDGs including certainly health, life under water, life on land, food security, and likely more. And the location of intervention matters (e.g., surface-based interventions could result in substantial waste in otherwise pristine areas).

\section{Implications of SRM deployment policies through social, economic, and political impact pathways}

Non-physical impact pathways concern economic productivity and the availability of public budgets, social distribution, participation, health, gender, cultural, legal, institutional, and global governance dimensions.

\subsection{Economic impacts - public costs of various approaches}

In light of the public good nature of SRM, costs for SRM are likely to have to be covered by the public sector thereby in principle competing for budgets with other publicly funded matters relevant to sustainable development such as the humanitarian sector (Suarez and 


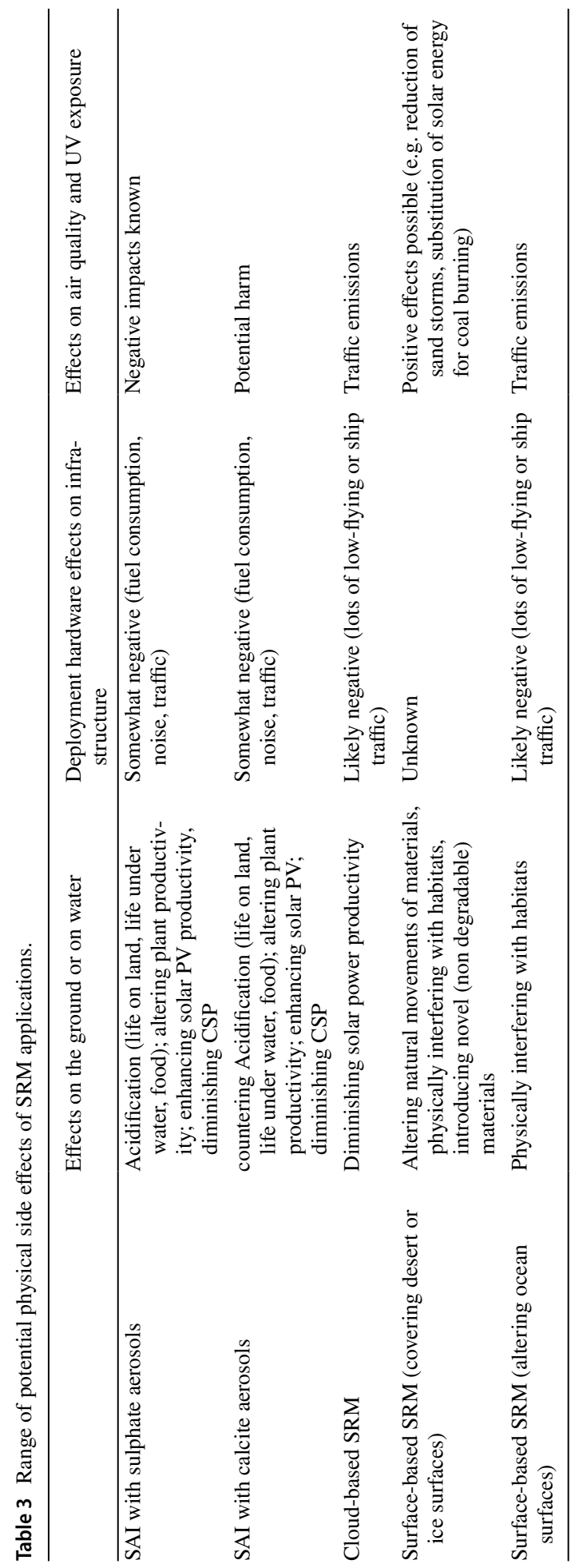


van Aalst, 2017). Yet, successful SRM application could potentially reduce actual spending needs for adaptation (which in a $3{ }^{\circ} \mathrm{C}$ warmer world is expected to dramatically increase) thus freeing up public budgets for other efforts to advance sustainable development.

SAI global deployment costs not including accompanying measures have been estimated (if using specifically designed new aircraft) at US\$2.25-10 billion per year (Smith and Wagner, 2018; Moriyama et al., 2017). Overall costs of deployment would however be higher if accounting for global policy coordination, observation and modelling efforts, security measures, and necessary redundancies in the delivery equipment (Reynolds et al., 2016). Potential demands for compensation for side effects could also be substantial (Horton et al., 2014). Given its inherently global nature, some form of agreement of burden sharing for SAI costs would have to be found, but any large country facing potentially significant damages from climate change would principally be able to shoulder these costs even if no cooperation is forthcoming.

For cloud modifications, cost estimates are currently lacking given vast uncertainties over various delivery mechanisms' efficacy and the associated uncertainty over the necessary volumes for delivery of specified radiative forcing particularly in light of complex microphysical interactions between aerosols, and vertical airmass movements affecting nucleation processes (Gasparini and Lohmann, 2016).

For the category of surface albedo modifications, costs likely diverge strongly depending on the type of measure taken. To date, surface albedo modification has in practice not systematically been addressed as a climate modification technique and there is no consolidated literature on estimates of its cost. By consequence, we disregard the cost-aspect of large-scale surface albedo modifications for the purposes of this review as in practice such action (modifications in agricultural or forestry practices, selecting particular crops for having a higher reflectivity, etc.) would likely only be taken with other objectives (and corresponding funding) in mind (Seneviratne et al., 2018).

\subsection{Social implications}

A key question is how social impacts relate to the geographic distribution of change across key climate variables, which hold potential to strongly influence outcomes for the poor (SDG 1), for agricultural yields (SDG 2), human health (SDG 3), and economic productivity (SDG 8). An even distribution of reductions in change of key climate parameters could strongly benefit poor and vulnerable populations who are otherwise feared to suffer the most from climate change. Uneven distributions of climatic outcomes or damage of key ecosystems and planetary functions could potentially disproportionately disadvantage poor populations most dependent on ecosystem services and with less means to protect themselves if regional differences are optimized for the benefit of powerful strata of populations. SRM done in ways that enhance rather than erode ecosystem services and agricultural productivity (e.g., countering acidification or strengthening plant productivity through diffuse light; Xia et al., 2016) would likely disproportionately benefit the poor, who otherwise would suffer the most from ongoing ecosystem and agricultural degradation. Any changes to the prices of commodities whose production is strengthened or reduced or demand for which is in- or decreased due to SRM, particularly food products, would likely disproportionally weigh on- or benefit the poor (SDG 1,2,8).

In view of the importance of the local context (such as socio-economic, political, cultural, environmental, and climatic), inclusive, and broad-based research and deliberation is a necessity for gaining better understanding of the implications of SRM in various 
geographies. Given that institutions based in developing economies may not prioritize such activities over other urgent issues of concern, financial support from the global North may be required to enable the necessary participation (Rahman et al., 2018; Frumhoff and Stephens, 2018). Strengthened efforts to enable involvement of developing country research institutions and a broad range of stakeholders in SRM research could be important to avoid exacerbating or creating new inequalities.

Women are currently underrepresented among SRM researchers. Research quality, governance considerations, and later policy design would likely benefit from better gender balance, broadening the range of assessment metrics in use (e.g., beyond cost-benefit and risk categories), and by introducing a broader range of ethical concepts to the dilemmas posed by these technologies (Buck et al., 2014).

\subsection{Legal and institutional implications}

The emergence of a largely new and urgent global governance challenge requiring a significant level of global agreement and cooperation could both strain global institutions as well as create linkages and solutions helpful to analogous approaches in other fields with global governance challenges (Nicholson et al., 2018) including, e.g., strengthened public participation (Frumhoff and Stephens, 2018) (SDGs 16, 17). Institutional mandates are, however, not clear (especially for globally effective SRM) as the range of governance challenges such interventions pose does not fit a singular governance context (Bodansky, 2013; Honegger et al., 2013). Rather, the transboundary nature of potential SRM effects on humans and the environment requires involvement of international governance institutions including those addressing climate change, the environment in general, biodiversity, oceans, human rights, and more (Reynolds, 2019). Additionally, also national institutions may need to address questions around research or deployment.

Numerous global governance institutions have to date been involved or evoked as potentially relevant to governance of SRM. Their respective role toward SRM interventions is intertwined with the nature of the intervention as well as potential outcomes: The degree to which SAI for example would contribute to acidification or in fact actively counter present acidification trends (depending on the materials proposed) would concern UN Environment, FAO, CBD, or the London Convention and Protocol.

\subsection{Implications for international collaboration and peace}

The need to agree a common temperature goal that would accommodate diverging national interests could test the capability of international institutions. Some see this as a potential new source of international conflict and disagreement affecting SDG 16 (Macnaghten and Szerszynski, 2013). Also, transboundary side effects could result in tensions and pose challenges for international institutions. If not founded on a strong basis of international support, SRM applications could in principle be counteracted through various technical means including via the release of potent industrial GHGs or via the destruction of deployment equipment by military intervention (Parker and Irvine, 2018).

It is unclear whether SRM would require more centralized or dispersed forms of global governance and whether it would concentrate or disperse power globally due to the relative affordability of the technology (Reynolds, 2018). The need for international collaboration arising from SRM application (e.g., collective efforts for monitoring and verification of SRM effects) could result in strengthening of international collaboration 
and partnership for the goals (SDG 17). But a loss of trust and collaboration between networks of international institutions working toward human development and reducing climate impacts could also result.

If regional differences in side effects arise, legal challenges might emerge in attributing causality in the context of claims for compensation for relative losses. If consideration of SRM resulted in lessened political will to reduce fossil fuel use, substantial health benefits due to reductions in respiratory disease from particulate matter pollution would be reduced or lost. If impetus for climate action was enhanced, however, benefits associated with reducing combustion of fossil fuels would be accelerated as well (SDGs $2,13,14,15)$.

\subsection{Summary of identified implications}

The potential implications identified for the SDGs are likely to differ strongly depending on the assumed scale of SRM deployment as well as the policy pathways and broader governance contexts. Significant gaps in knowledge mean that a comprehensive discussion of pros and cons for each technology (or combinations of technologies) is still far from possible at this stage.

Any successful deployment of SRM that achieves reduction of change across all key climate change variables is expected to reduce climate change impacts on attainment of all 17 SDGs. Further implications (positive and negative) arise from physical side effects as well as socio-economic, political, and cultural impact pathways for at least 13 out of 17 SDGs. Yet SRM deployment could also cause risks for the successful delivery of more than half of all SDGs (at least 9 out of 17 SDGs) including: SDG-6 (Clean Water and Sanitation), SDG-3 (Good Health and Well-being), SDG-1 (No poverty), and SDG-16 (Peace, Justice and Strong Institutions). Further risks are also identified for delivery of SDG-2 (Zero hunger), SDG-14 (Life below water), SDG-7 (Affordable and clean energy), SDG-8 (Decent work and economic growth), and SDG-15 (Life on land).

A detailed goal-by-goal and point-by-point list of potential implications (Fig. 3) is provided in the supporting material.

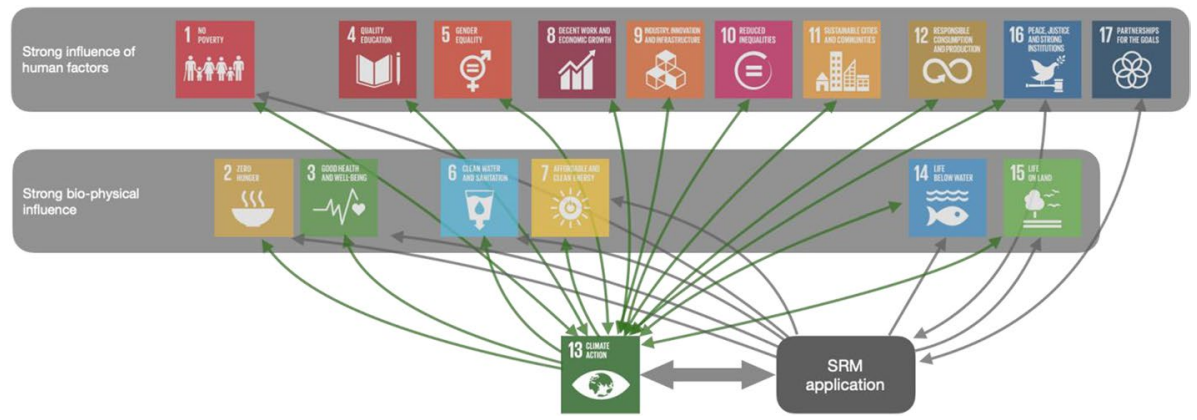

Fig. 3 A summary illustration of the main identified ways in which SRM applications could potentially interact with SDGs (full list provided in supporting material). Our review finds SRM (side-) effects (grey arrows) and effects from modulating the climate system (green arrows, see also Table 2). Some impact pathways are predominantly (bio-) physical (esp. on SDGs in the middle tier) or more strongly modulated by human factors (social, economic, political, or cultural; esp. on SDGs in the upper tier) 


\section{Conclusions}

While this review presents some early insights into potential benefits and negative impacts of deploying SRM technologies, focusing on SAI, it is important to note that decisions both for or against pursuing research or deployment of such technologies will also have significant implications for delivery of the SDGs to a greater or lesser extent as climate change impacts progress. Any kind of cost-benefit analysis to inform considerations of whether or not to deploy such technologies in the future will require a considerably more detailed, transdisciplinary assessment of implications for SDG delivery.

Our review highlights the interconnections between potential effects of SRM application intended to limit climate change-related damages, and the multiplicity of objectives embedded in the SDGs. While finding numerous indications of potential effects - positive and negative - we also encounter significant barriers to building a strong foundation of understanding on which later decision making can be built.

Climate change and its effects are frequently studied in models and discussion of SRM, especially SAI, is rooted in earth system modelling, which is best suited to gain understanding of climate change across physical parameters. Second-order implications from various climate states are often modelled in climate impact models, whereby physical variables are translated into economic costs and benefits. SRM cost-benefit could in principle also be modelled in such a way. However, such simplification misses fundamental interrelations between physical and non-physical impact pathways: To further explore these, more transdisciplinary and geographically diverse research is required on the interconnections between SRM and sustainable development. Development of common assessment principles or metrics spanning the SDG dimensions might also allow further exploration of the more indirect interrelations, including by quantitative analysis of potential risks and benefits of SRM to avoid under- or over-estimating climate and sustainable development impacts. In light of controversy on the role of science itself in the generation of societally relevant knowledge, also more social science and humanities research may be needed, including critical reflection on the role of science and technology in the context of achieving the SDGs.

In the longer term, more integrated policy impact assessments might be required to explore intricacies of potential policy designs seeking to mobilize, regulate, monitor, and report on SRM, and their potential implications for delivery of the SDGs, particularly for international cooperation and partnerships for the goals. In the near term, governance of research on SRM also requires more attention in light of the necessity to ensure research can progress - in a way that advances societal objectives and public interests of present and future generations.

Supplementary Information The online version contains supplementary material available at https://doi. org/10.1007/s11027-021-09958-1.

Acknowledgements This work was supported by the Carnegie Climate Governance Initiative (C2G). The views expressed in this article are those of the authors and do not necessarily represent those of C2G.

Open Access This article is licensed under a Creative Commons Attribution 4.0 International License, which permits use, sharing, adaptation, distribution and reproduction in any medium or format, as long as you give appropriate credit to the original author(s) and the source, provide a link to the Creative Commons licence, and indicate if changes were made. The images or other third party material in this article are included in the article's Creative Commons licence, unless indicated otherwise in a credit line to the material. If material is not included in the article's Creative Commons licence and your intended use is not 
permitted by statutory regulation or exceeds the permitted use, you will need to obtain permission directly from the copyright holder. To view a copy of this licence, visit http://creativecommons.org/licenses/by/4.0/.

\section{References}

Alterskjær K, Kristjánsson JE, Boucher O, Muri H, Niemeier U, Schmidt H, Schulz M, Timmreck C (2013) Sea-salt injections into the low-latitude marine boundary layer: the transient response in three Earth system models. J Geophys Res Atmos 118:12195-12206

Ansuategi A, Greno P, Houlden, V, Markandya A, Onofri L, Picot H, Walmsley N (2015) The impact of climate change on the achievement of the post-2015 sustainable development goals. HR Wallingford, Metroeconomica \& CDKN report, Amsterdam, Netherlands.

Barnes PW, Williamson CE, Lucas RM, Robinson SA, Madronich S, Paul ND ... Zepp RG (2019) Ozone depletion, ultraviolet radiation, climate change and prospects for a sustainable future. Nat Sustain 2(7):569-579

Belaia M, Funke M, Glanemann N (2017) Global warming and a potential tipping point in the Atlantic thermohaline circulation: the role of risk aversion. Environ Resourc Econ 67:93-125

Bellamy R (2018) Incentivize negative emissions responsibly. Nat Energy 3(7):532-534

Bodansky D (2013) The who, what, and wherefore of geoengineering governance. Clim Change 121:539-551

Buck HJ, Gammon AR, Preston CJ (2014) Gender and geoengineering. Hypatia 29:651-669

Curry CL, Sillmann J, Bronaugh D, Alterskjaer K, Cole JN, Ji D, Kravitz B, Kristjánsson JE, Moore JC, Muri H, Niemeier U (2014) A multimodel examination of climate extremes in an idealized geoengineering experiment. J Geophys Res Atmos 119:3900-3923

Cziczo DJ, Wolf MJ, Gasparini B, Münch S, Lohmann U (2019) Unanticipated side effects of stratospheric albedo modification proposals due to aerosol composition and phase. Sci Rep 9(1):1-7

Cziczo DJ, Froyd KD, Hoose C, Jensen EJ, Diao M, Zondlo MA, Smith JB, Twohy CH, Murphy DM (2013) Clarifying the dominant sources and mechanisms of cirrus cloud formation. Science 340:1320-1324

Dai Z, Weisenstein DK, Keutsch FN, Keith DW (2020) Experimental reaction rates constrain estimates of ozone response to calcium carbonate geoengineering. Comm Earth Environ 1(1):1-9

Dankelman I (2002) Climate change: learning from gender analysis and women's experiences of organising for sustainable development. Gend Dev 10:21-29

Eastham SD, Weisenstein DK, Keith DW, Barrett SR (2018) Quantifying the impact of sulfate geoengineering on mortality from air quality and UV-B exposure. Atmos Environ 187:424-434

Effiong U, Neitzel RL (2016) Assessing the direct occupational and public health impacts of solar radiation management with stratospheric aerosols. Environ Health 15(7):1-9

Ferraro AJ, Charlton-Perez AJ, Highwood EJ (2014) A risk-based framework for assessing the effectiveness of stratospheric aerosol geoengineering. PLoS ONE 9(2):1-6

Frumhoff PC, Stephens JC (2018) Towards legitimacy of the solar geoengineering research enterprise. Philos Trans R Soc A376.

Fink JH (2013) Geoengineering cities to stabilise the climate. Proc Instit Civil Eng Eng Sustain 166:242-248

Gasparini B, Lohmann U (2016) Why cirrus cloud seeding cannot substantially cool the planet. J Geophys Res Atmos 121(9):4877-4893

Glewwe P (2005) The impact of child health and nutrition on education in developing countries: theory, econometric issues, and recent empirical evidence. Food Nutr Bull 26:S235-S250

Haddeland I, Heinke J, Biemans H, Eisner S, Flörke M, Hanasaki N, Konzmann M, Ludwig F, Masaki Y, Schewe J, Stacke T (2014) Global water resources affected by human interventions and climate change. Proc Natl Acad Sci 111(9):3251-3256

Honegger M, Derwent H, Harrison N, Michaelowa A, Schäfer S (2018) Carbon removal and solar geoengineering: potential implications for delivery of the sustainable development goals. Carnegie Climate Geoengineering Governance Initiative, May 2018, New York, U.S.

Honegger M, Sugathapala K, Michaelowa A (2013) Tackling climate change: where can the generic framework be located? Carbon \& Climate Law Review 7(2):125-135

Honegger M, Reiner D (2017) The political economy of negative emissions technologies: consequences for international policy design. Clim Policy 18:306-321

Horton JB, Parker A, Keith D (2014) Liability for solar geoengineering: historical precedents, contemporary innovations, and governance possibilities. NYU Environ Law J 22:225-275 
IEA (International Energy Agency) (2020) CO2 emissions from fossil fuel combustion. International Energy Agency, OECD, Paris.

Irvine P, Emanuel K, He J, Horowitz LW, Vecchi G, Keith D (2019) Halving warming with idealized solar geoengineering moderates key climate hazards. Nat Clim Chang 9(4):295-299

Irvine PJ, Sriver RL, Keller K (2012) Tension between reducing sea-level rise and global warming through solar-radiation management. Nat Clim Chang 2:97-100

Irvine PJ, Ridgwell A, Lunt DJ (2010) Assessing the regional disparities in geoengineering impacts. Geophys Res Lett 37:1-6

Jandaghian Z, Akbari H (2018) The effect of increasing surface albedo on urban climate and air quality: a detailed study for Sacramento, Houston, and Chicago. Climate 6:19

Jones A, Hawcroft M, Haywood J, Guo X, Moore J (2018) Regional climate impacts of stabilizing global warming at $1.5 \mathrm{~K}$ using solar geoengineering. Earth's Future 6(2):230-251

Jones A, Haywood J, Boucher O (2011) A comparison of the climate impacts of geoengineering by stratospheric SO2 injection and by brightening of marine stratocumulus cloud. Atmospheric Science Letters 12:176-183

Keith DW, Weisenstein DK, Dykema JA, Keutsch FN (2016) Stratospheric solar geoengineering without ozone loss. Proc Natl Acad Sci 113:14910-14914

Keith D, MacMartin D (2015) A temporary, moderate and responsive scenario for solar geoengineering. Nat Clim Chang 5(3):201-206

Kravitz B, MacMartin DG, Tilmes S, Richter JH, Mills MJ, Cheng W., ... \& Vitt F (2019) Comparing surface and stratospheric impacts of geoengineering with different SO2 injection strategies. J Geophys Res Atmos 124(14), 7900-7918.

Kravitz B, MacMartin DG, Mills MJ, Richter JH, Tilmes S, Lamarque JF, ... \& Vitt F (2017) First simulations of designing stratospheric sulfate aerosol geoengineering to meet multiple simultaneous climate objectives. J Geophys Res Atmos 122(23), 12-616.

Kravitz B, Robock A, Oman L, Stenchikov G, Marquardt AB (2009) Sulfuric acid deposition from stratospheric geoengineering with sulfate aerosols. J Geophys Res Atmos 114:1-7

Kwiatkowski L, Cox P, Halloran PR, Mumby PJ, Wiltshire AJ (2015) Coral bleaching under unconventional scenarios of climate warming and ocean acidification. Nat Clim Chang 5:777-781

Lawrence MG, Schäfer S, Muri H, Scott V, Oschlies A, Vaughan NE, Boucher O, Schmidt H, Haywood J, Scheffran J (2018) Evaluating climate geoengineering proposals in the context of the Paris Agreement temperature goals. Nat Commun 9(1):1-19

Lohmann U, Gasparini B (2017) A cirrus cloud climate dial? Science 357:248-249

MacMartin DG, Ricke KL, Keith DW (2018) Solar geoengineering as part of an overall strategy for meeting the $1.5^{\circ} \mathrm{C}$ Paris target. Philos Trans R Soc London A 376:1-19

Macnaghten P, Szerszynski B (2013) Living the global social experiment: an analysis of public discourse on solar radiation management and its implications for governance. Glob Environ Chang 23:465-474

Marshall M (2013) Get cirrus in the fight against climate change. New Scientist Environ 2901:14

Michaelowa A, Allen M, Sha F (2018) Policy instruments for limiting global temperature rise to $1.5^{\circ} \mathrm{C}$ - can humanity rise to the challenge? Clim Policy 18:275-286

Moore FC, Diaz DB (2015) Temperature impacts on economic growth warrant stringent mitigation policy. Nat Clim Chang 5:127-131

Moriyama R, Sugiyama M, Kurosawa A, Masuda K, Tsuzuki K, Ishimoto Y (2017) The cost of stratospheric climate engineering revisited. Mitig Adapt Strat Glob Change 22(8):1207-1228

Morrow DR (2014) Ethical aspects of the mitigation obstruction argument against climate engineering research. Philos Trans R Soc A 372(2031):20140062

Muri H, Tjiputra J, Otterå OH, Adakudlu M, Lauvset SK, Grini A, Schulz M, Niemeier U, Kristjánsson JE (2018) Climate response to aerosol geoengineering: a multimethod comparison. J Clim 31(16):6319-6340

Muri H, Niemeier U, Kristjánsson JE (2015) Tropical rainforest response to marine sky brightening climate engineering. Geophys Res Lett 42:2951-2960

National Academies of Science (2015) Climate intervention: reflecting sunlight to cool earth. National Academies Press, Washington, DC

Nerini FF, Sovacool B, Hughes N, Cozzi L, Cosgrave E, Howells M, Tavoni M, Tomei J, Zerriffi H, Milligan B (2019) Connecting climate action with other sustainable development goals. Nat Sustain 2(8):674-680

Nicholson S, Jinnah S, Gillespie A (2018) Solar radiation management: a proposal for immediate polycentric governance. Clim Policy 18(3):322-334 
Nowack PJ, Abraham NL, Braesicke P, Pyle JA (2016) Stratospheric ozone changes under solar geoengineering: implications for UV exposure and air quality. Atmos Chem Phys 16:4191-4203

Pan J (2020a) Lower carbon emission peak with orientation towards zero carbon. J Environ Econ (No 4: 1-10, In Chinese, with English Abstract, https://doi.org/10.19511/j.cnki.jee.2020.04.001)

Pan J (2020b) Meeting SDGs through paradigm shift in the evolving world pattern. In T. Meyer, J. S. Marques, and M. Telo (eds), Towards a new multilateralism? Cultural Diversity and Political Cooperation?. Springer 2020 (forthcoming)

Parker A, Irvine PJ (2018) The risk of termination shock from solar geoengineering. Earth's Future $6(3): 456-467$

Pitari G, Aquila V, Kravitz B, Robock A, Watanabe S, Cionni I, Luca ND, Genova GD, Mancini E, Tilmes S (2014) Stratospheric ozone response to sulfate geoengineering: results from the Geoengineering Model Intercomparison Project (GeoMIP). J Geophys Res Atmos 119:2629-2653

Poloczanska ES, Burrows MT, Brown CJ, García Molinos J, Halpern BS, Hoegh-Guldberg O, Kappel CV, Moore PJ, Richardson AJ, Schoeman DS, Sydeman WJ (2016) Responses of marine organisms to climate change across oceans. Front Mar Sci 3:1-21

Pretis F, Schwarz M, Tang K, Haustein K, Allen M (2018) Uncertain impacts on economic growth when stabilizing global temperatures at $1.5^{\circ} \mathrm{C}$ or $2^{\circ} \mathrm{C}$ warming. Phil Trans R Soc A 376:1-31

Rahman AA, Artaxo P, Asrat A, Parker A (2018) Developing countries must lead on solar geoengineering research. Nature 556:22-24

Rasch PJ (2010) Technical fixes and climate change: optimizing for risks and consequences. Environ Res Lett 5:031001

Rasch PJ, Tilmes S, Turco RP, Robock A, Oman L, Chen CC, Stenchikov GL, Garcia RR (2008) An overview of geoengineering of climate using stratospheric sulphate aerosols. Phil Trans R Soc A 366:4007-4037

Reynolds JL (2019) The governance of solar geoengineering: managing climate change in the Anthropocene. Cambridge University Press

Reynolds J (2018) Governing experimental responses: negative emissions technologies and solar climate engineering. In Governing Climate Change: Policentricity in Action? (pp. 285-302, Jordan A, Huitema D, van Asselt H (eds). Cambridge University Press, Cambridge.

Reynolds JL, Parker A, Irvine P (2016) Five solar geoengineering tropes that have outstayed their welcome. Earth's Future 4(12):562-568

Ricke KL, Morgan MG, Allen MR (2010) Regional climate response to solar-radiation management. Nat Geosci 3:537-541

Royal Society (2009) Geoengineering the climate - science, governance and uncertainty. Royal Society Policy document 10/09, London.

Schäfer S, Lawrence M, Stelzer H, Born W, Low S, Aaheim A, Adriázola P, Betz G, Boucher O, Carius A, Devine-Right P (2015) The European transdisciplinary assessment of climate engineering (EuTRACE). Removing Greenhouse Gases from the Atmosphere and Reflecting Sunlight away from Earth. Berlin.

Seneviratne S, Phipps S, Pitman A, Hirsch A, Davin E, Donat M, Hirschi M, Lenton A, Wilhelm M, Kravitz B (2018) Land radiative management as contributor to regional-scale climate adaptation and mitigation. Nat Geosci 11:88-96

Smith W, Wagner G (2018) Stratospheric aerosol injection tactics and costs in the first 15 years of deployment. Environ Res Lett 13(12):124001

Smith CJ, Crook JA, Crook R, Jackson LS, Osprey SM, Forster PM (2017) Impacts of stratospheric sulfate geoengineering on global solar photovoltaic and concentrating solar power resource. J Appl Meteorol Climatol 56:1483-1497

Storelvmo T, Herger N (2014) Cirrus cloud susceptibility to the injection of ice nuclei in the upper troposphere. J Geophys Res Atmos 119:2375-2389

Suarez P, van Aalst MK (2017) Geoengineering: a humanitarian concern. Earth Future 5:183-195

Tilmes S, Fasullo J, Lamarque JF, Marsh DR, Mills M, Alterskjær K, Muri H, Kristjánsson JE, Boucher O, Schulz M, Cole JN (2013) The hydrological impact of geoengineering in the Geoengineering Model Intercomparison Project (GeoMIP). J Geophys Res Atmos 118(19):11-036

Trisos CH, Amatulli G, Gurevitch J, Robock A, Xia L, Zambri B (2018) Potentially dangerous consequences for biodiversity of solar geoengineering implementation and termination. Nat Ecol Evolut 1:475-482

Van Vliet MT, Wiberg D, Leduc S, Riahi K (2016) Power-generation system vulnerability and adaptation to changes in climate and water resources. Nat Clim Chang 6:375

Visioni D, Pitari G, Tuccella P, Curci G (2018) Sulfur deposition changes under sulfate geoengineering conditions: quasi-biennial oscillation effects on the transport and lifetime of stratospheric aerosols. Atmos Chem Phys 18(4):2787-2808 
WHO, WMO (2012) Atlas of health and climate. WMO-No. 1098, World Health Organization and World Meteorological Organization, Geneva.

World Bank (2016a) Emerging trends in mainstreaming climate resilience in large scale, multi-sector infrastructure PPPs. The World Bank, Washington DC

World Bank (2016b) Shock waves: managing the impacts of climate change on poverty, climate change and development series. Washington DC.

Xia L, Robock A, Tilmes S, Neely RR III (2016) Stratospheric sulfate geoengineering could enhance the terrestrial photosynthesis rate. Atmos Chem Phys 16:1479-1489

Publisher's note Springer Nature remains neutral with regard to jurisdictional claims in published maps and institutional affiliations. 